\title{
Effect of Olmesartan on the Level of Oral Cancer Risk Factor PAI1
}

\author{
STAVROS VASSILIOU ${ }^{1}$, EMEKA NKENKE ${ }^{2}$, NIKOS LEFANTZIS ${ }^{1}$, ANASTASIOS IOANNIDIS ${ }^{3,4}$, \\ CHRISTOS YAPIJAKIS ${ }^{1,5}$, MARGARITA ZOGA $^{4}$,VERONICA PAPAKOSTA ${ }^{1}$, \\ SPYRIDOULA DERKA ${ }^{1}$, CHRYSSOULA NIKOLAOU $^{4}$ and ELEFTHERIOS VAIRAKTARIS ${ }^{1}$ \\ ${ }^{1}$ Department of Oral and Maxillofacial Surgery, National and Kapodistrian University of Athens, \\ Medical School, Attikon Hospital, Chaidari, Athens, Greece; \\ ${ }^{2}$ Department of Oral and Maxillofacial Surgery, University of Vienna, Vienna, Austria; \\ ${ }^{3}$ Department of Nursing, Faculty of Human Movement and Quality of Life Sciences, \\ University of Peloponnese, Sparta, Greece; \\ ${ }^{4}$ Department of Biopathology and Clinical Microbiology, and ${ }^{5}$ First Department of Neurology, \\ National and Kapodistrian University of Athens, Medical School, Eginition Hospital, Athens, Greece
}

\begin{abstract}
Aim: To study if the angiotensin receptor blocker olmesartan reduces levels of plasminogen activator inhibitor 1 (PAI1), a risk factor for oral cancer, in a mouse model and therefore whether it could be used in the treatment of this malignancy. Materials and Methods: Twelve transgenic PAII mice aged 16-20 weeks were divided in two groups each containing six animals. One group was given olmesartan every day for 30 days in drinking water in an amount corresponding to their weight, $0.005 \mathrm{mg} / \mathrm{g}$, while the second group did not receive any medication (control group). Blood samples were obtained from animals of both groups, before and after one month of olmesartan administration and plasma PAII levels were measured using enzyme-linked immunosorbent assay. Results: In the olmesartan-treated group, a significant decrease of PAIl level was found after 1 month of treatment $(11.9 \pm 8.6 \mathrm{vs}$. $21.7 \pm 7.2 \mathrm{ng} / \mathrm{ml}$, respectively; $p=0.028)$. However, no statistically significant difference was observed in PAII levels between the olmesartan-treated and control groups after one month, ( $p=0.177)$. Conclusion: Olmesartan did not significantly affect PAIl levels in this mouse model.
\end{abstract}

Oral cancer remains the sixth most common type of cancer and one of the leading causes of death, particularly in

Correspondence to: Assistant Professor Stavros Vassiliou, MD, DDS, Ph.D., Ph.D., Department of Oral and Maxillofacial Surgery, University of Athens Medical School, Attikon Hospital, Rimini 1, Chaidari GR - 12462, Athens, Greece. Tel: +30 2105831544, Fax: +302105831545, e-mail: stvasil@med.uoa.gr

Key Words: PAI-1, olmesartan, transgenic mice, oral cancer. developing countries. Oral squamous cell carcinoma encompasses more than $90 \%$ of oral malignancies and has been reported in all parts of the oral cavity (1). Approximately 350.000 people are diagnosed with this disease annually worldwide, while the 5-year survival rates are poor, ranging between $30-50 \%$ in different studies and have not changed during the past two decades $(2,3)$.

The development and progression of carcinogenesis in the oral region is a multistep process in which mutations in oncogenes and tumor-suppressor genes are involved, influenced by certain chemical factors such as plasminogen activator inhibitor-1 (PAI1). PAI1, also known as serpine, is emerging as a potential factor with an active role in oral carcinogenesis (2, 3). Many authors have correlated plasma PAI1 levels with the progression and development of oral cancer, although the mechanisms of its action are not yet fully understood $(4,5)$.

Olmesartan is an angiotensin II receptor antagonist indicated for the treatment of hypertension. Administration of olmesartan to patients with hypertension significantly reduced levels of PAI1 after 6 months of treatment (6). In addition, when olmesartan was administered at $10 \mathrm{mg} / \mathrm{kg}$ in drinking water of mice with subcutaneous tumors, inhibition of tumor growth was observed, thus the drug has been assigned a supporting role in anticancer therapy, especially in pancreatic cancer (7).

In an effort to examine the possible therapeutic role of olmesartan in PAI1-induced oral cancer, we studied an experimental animal model by administration of the angiotensin receptor blocker to transgenic mice overexpressing PAI1. The aim was to study the possible effect of olmesartan in reducing the PAI1 level in mice so that it could be used as a treatment model for oral cancer. 


\section{Materials and Methods}

Twelve transgenic PAI1 mice (Mus musculus; aP2 - PAI - Poly A 388, $50 \%$ FVB, 50\% B16; Heverlee, carrying human PAIl gene), ranging from 16 to 20 weeks of age, were transferred to Attikon Hospital Experimental Surgery and Surgical Research laboratory of Athens Medical School, from the Laboratory Animal Centre of the Catholic University of Leuven, Belgium. The animals were handled according to Greek legislation for the Care and Use of Laboratory Animals (P.D. 160/91 and Law 2015/92, conforming to European Directive 86/609) under controlled conditions with a 12-h light/dark cycle and maintained on a standard laboratory animal diet with constant nutrition (Mucedola s.r.l., Milan, Italy) and had free access to water. All animals were supervised by an experienced veterinary surgeon.

The mice were divided into two groups of six. The allocation to groups was random and both were matched with age, sex and race. The first group was given olmesartan, while the second group was not (control group). The drug was administered at the same time every day for 30 days in drinking water. In humans olmesartan is administered at a dosage of $0.5 \mathrm{mg} / \mathrm{kg}$, hence the drug was administered to mice at a dosage of $0.0005 \mathrm{mg} / \mathrm{g}$ weight. A $20 \mathrm{mg}$ tablet (olartan; Menarini International Operations Luxembourg SA, Luxembourg) was ground it and dissolved in water. Each mouse weighed an average of $500 \mathrm{~g}$ and was administered on average $0.25 \mathrm{mg}$ olmesartan once a day dissolved in $0.2 \mathrm{ml}$ of distilled water. After sedation with ketamine in dosage that did not hinder ingestion, the olmesartan solution was orally administered with an insulin syringe. Blood samples were taken from both groups, at the beginning and after a month of olmesartan administration. Samples were centrifuged and plasma PAI1 concentrations were determined with a commercially available sandwich enzyme immunoassay following the manufacturer's instructions (Cusabio Biotech Co. Ltd, College Park MD, USA). The assay's mean minimum detectable dose was less than $0.46 \mathrm{ng} / \mathrm{ml}$ and the detection range was between $1.87-120 \mathrm{ng} / \mathrm{ml}$ (Figure 1).

PAI1 levels were compared at these two times for the same group as well to the between the two groups. Statistical analysis for this comparison was performed using the Mann-Whitney $U$-test, while for the comparison of PAI1 levels for each group individually (at baseline and after one month), the Wilcoxon signed-rank test was used. The significance level was set at $p<0.05$.

\section{Results}

The results are shown in Table I. During the study one mouse in the control group died, thus group $\mathrm{C}$ included five animals. In the olmesartan-treated group, a statistically significant decrease of PAI1 level after 1 month of drug administration was found $(p=0.028)$. A similar significant decrease of PAI1 level after 1 month was also observed in the control group $(p=0.043)$. However, no statistical difference was observed between the two groups $(p=0.177)$.

\section{Discussion}

A significant correlation of high plasma PAI1 levels with the development and progression of oral cancer has been reported by our group and others, although the mechanisms of its action is not much clear (8-11). The plasminogen activator system consists of tissue-type plasminogen activator (t-PA) and urokinase-type plasminogen activator (u-PA), their inhibitors a2-anti-plasmin, PAI1 and PAI-2 and their receptors. By regulating t-PA and $\mathrm{u}-\mathrm{PA}$, PAI1 converts the inactive proenzyme plasminogen to the active plasmin, which in turn plays an important role in fibrinolysis and also in the zymogen activation of matrix metalloproteinases (MMPs), of which MMP2 and MMP9 have a special role in oral cancer. These proteases are produced by tumor cells and degrade the major components of the extracellular proteins. In addition, PAI1 binds to integrins, which are implicated in tumor progression and metastasis because they play an important role in the maintenance of tissue integrity and in the regulation of cell proliferation, growth, differentiation, and migration. Elevated levels of PAI1 lead to hypofibrinolysis, down-regulation of MMPs and decreased cellular adhesion $(5,12)$.

It is known that the angiotensin converting enzyme, and angiotensin II receptor type 1 and 2 contribute to cancer progression and lymph-node metastasis (13). Some studies have indicated that olmesartan, an effective angiotensin receptor blocker, significantly reduced levels of PAI1 and increased fibrinolytic capacity in blood, when administered to hypertensive patients $(6,11,14)$. Therefore, olmesartan might be used to reduce carcinogenic levels of PAI1, although the effect of this drug on PAI1 in cancer is unknown.

Although no animal model applies to any kind of human cancer perfectly, experimental animal models are of crucial importance to cancer research in general. The promising anticancer role of angiotensin receptor blockers has been previously observed in animal models (15). In particular, olmesartan administration for 26 weeks in transgenic mice showed neither de novo lung tumors nor promotion of background lung tumors (15). In addition, olmesartan reportedly inhibited growth of pancreatic carcinoma-related subcutaneous tumors in mice (7).

In an effort to examine the role of PAI1 in oral carcinogenesis and further investigate whether olmesartan could help in its treatment, we studied transgenic mice overexpressing PAI1. In a pilot study, we examined the effect of olmesartan in PAI1 levels in transgenic mice overexpressing PAI1 before inducing carcinogenesis. To our knowledge, there has been no similar animal study for oral cancer.

In our study, after one month of daily olmesartan administration, a statistically significant decrease of PAI1 was observed in the transgenic PAI1 overexpressing mice ( $21.7 \pm 7.2$ reduced to $11.9 \pm 8.6 \mathrm{ng} / \mathrm{ml}, p=0.028)$. However, there was no statistically significant difference in the group treated with olmesartan compared to the control group.

Despite an initial report of tumor growth-inhibiting effect of olmesartan in mice with pancreatic cancer-related subcutaneous tumors (7), further studies are needed in order to determine the anticancer effect of this drug. Especiallly in 


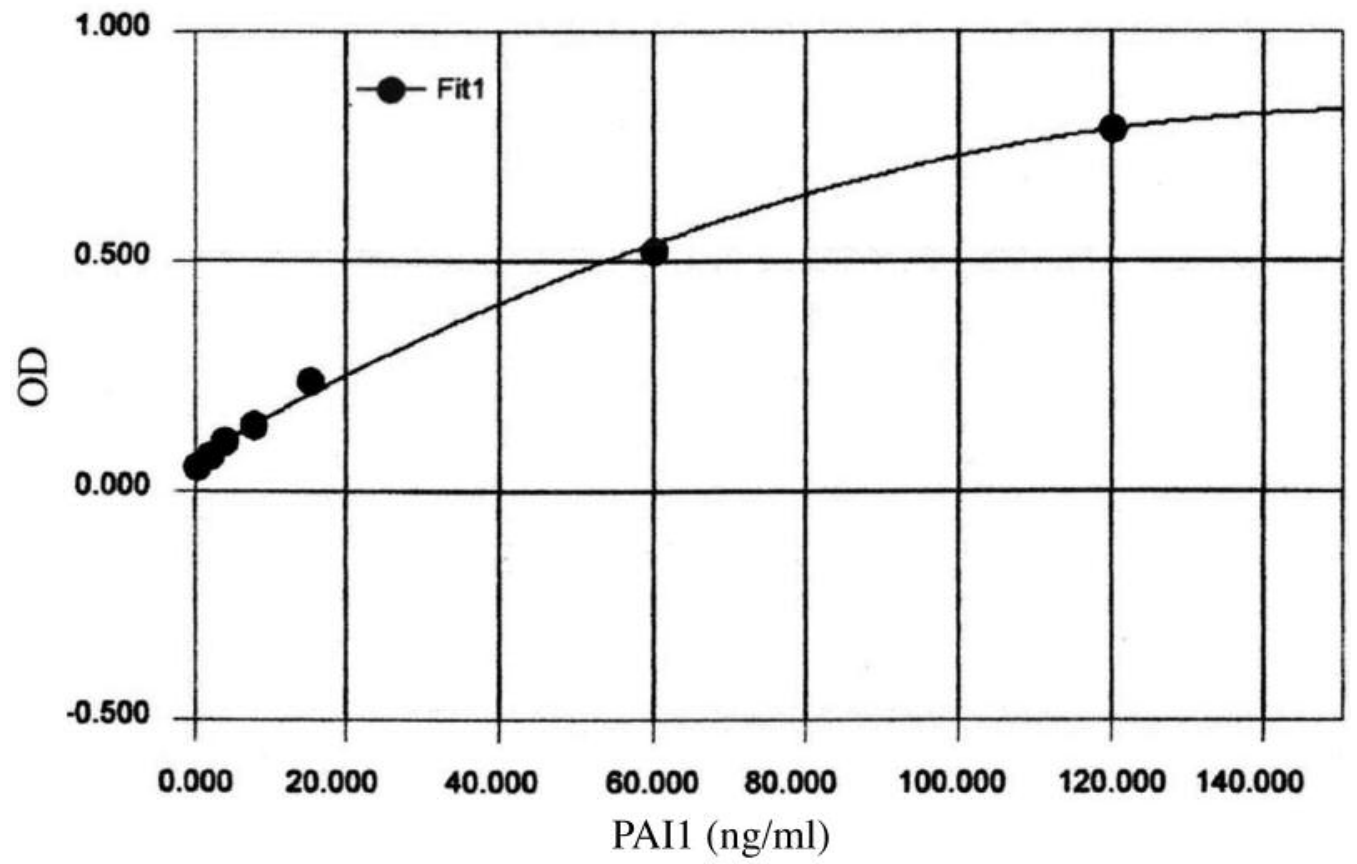

Figure 1. Observed optical density (OD) versus plasminogen activator inhibitor-1 (PAI1) concentration (ng/ml). The minimum detectable dose was $<0.46 \mathrm{ng} / \mathrm{ml}$ and the detection range was between $1.87 \mathrm{ng} / \mathrm{ml}-120 \mathrm{ng} / \mathrm{ml}$.

Table I. Comparison between olmesartan-treated and control groups.

\begin{tabular}{lccc}
\hline Timepoint & Group & Mean & $\begin{array}{c}\text { PAI1 (ng/ml) } \\
\text { Standard deviation }\end{array}$ \\
\hline Baseline & Olmesartan & 21.7 & 7.2 \\
After 1 month & Control & 17.8 & 3.2 \\
& Olmesartan & 11.9 & 8.6 \\
Baseline vs. 1 month & Control & 7.2 & 4.6 \\
At baseline & Olmesartan & & 0.028 \\
At 1 month & Control & & 0.043 \\
& Olmesartan vs. control & & 0.394 \\
\end{tabular}

PAI1: Plasminogen activator inhibitor 1.

oral cancer, it remains to be seen whether it could be included in the therapeutic arsenal.

\section{References}

1 Mognetti B, Di Carlo F and Berta GN: Animal models in oral cancer research. Oral Oncol 42: 448-460, 2006.

2 Tang XH, Knudsen B, Bemis D, Tickoo S and Gudas LJ: Oral cavity and esophageal carcinogenesis modeled in carcinogentreated mice. Clin Cancer Res 10(1 Pt 1): 301-313, 2004.

3 Hu B, Zhang C, Baawo K, Qin R, Cole GJ, Lee JA and Chen X: Zebrafish K5 promoter-driven GFP expression as a transgenic system for oral research. Oral Oncol 46: 31-37, 2010.
4 Wollenberg B, Jan NV, Jund R, Chaubal S and Untch M: Urokinase-type plasminogen activator and its inhibitor plasminogen activator inhibitor-1: New functional risk factors in head and neck squamous cell cancer. Oncol Rep 4: 853-855, 1997.

5 Bulur S, Ozhan H, Erden I, Alemdar R, Aydin M, Caglar O, Basar C and Ordu S: Efficacy of olmesartan therapy on fibrinolytic capacity in patients with hypertension. Blood Coag Fibrin 22: 29-33, 2011.

6 Masamune A, Hamada S, Kikuta K, Takikawa T, Miura S, Nakano $\mathrm{E}$ and Shimosegawa T: The angiotensin II type I receptor blocker olmesartan inhibits the growth of pancreatic cancer by targeting stellate cell activities in mice. Scand $\mathbf{J}$ Gastroenterol 48: 602-609, 2013. 
7 Hundsdorfer B, Zeilhofer, Bock KP, Dettmar P, Schmitt M, Kolk A, Pautke $\mathrm{C}$ and Horch $\mathrm{HH}$ : Tumor-associated urokinase-type plasminogen activator (UPA) and its inhibitor PAI1 in normal and neoplastic tissues of patients with squamous cell cancer of the oral cavity - clinical relevance and prognostic value. J Craniomaxillofac Surg 33: 191-196, 2005.

8 Baker EA, Leaper DJ, Hayter JP and Dickenson AJ: Plasminogen activator system in oral squamous cell carcinoma. Br J Oral Maxillofac Surg 45: 623-627, 2007.

9 Morgan H and Hill PA: Human breast cancer cell-mediated bone collagen degradation requires plasminogen activation and matrix metalloproteinase activity. Cancer Cell Int 5: 1-10, 2005.

10 Vairaktaris E, Yapijakis C, Serefoglou Z, Vylliotis A, Ries J, Nkenke E, Wiltfang J, Derka S, Vassiliou S, Springer I, Kessler $\mathrm{P}$ and Neukam FW: Plasminogen activator inhibitor-1 polymorphism is associated with increased risk for oral cancer. Oral Oncol 42: 888-892, 2006.

11 Merchant N, Rahman ST, Ahmad M, Parrott JM, Johnson J, Ferdinand K C and Khan BV: Changes in biomarkers and 24hour blood pressure in hypertensive African Americans with the metabolic syndrome: Comparison of amilodipine/olmesartan versus hydrochlorothiazide/losartan. J Am Soc Hyper 7: 386394, 2013.
12 Carl-McGrath S, Ebert MP, Lendeckel U and Röcken C: Expression of the local angiotensin II system in gastric cancer may facilitate lymphatic invasion and nodal spread. Cancer Biol Ther 6: 1218-1226, 2007.

13 Şendur MAN, Góven GS, Yorgun H, Ateş AH, Canpolat U, Sunman H, Karahan S, Kaya B and Aytemir K: Effect of antihypertensive therapy on endothelial markers in newly diagnosed Stage 1 hypertension: a randomized single-centre study. Anadolu Kardiyol Derg 14: 363-369, 2014.

14 Andreasen PA, Kjøller L, Christensen L and Duffy MJ: The urokinase-type plasminogen activator system in cancer metastasis: A review. Int. J. Cancer 72: 1-722, 1997.

15 Link WT and De Felice A: An FDA overview of rodent carcinogenicity studies of angiotensin II AT-1 receptor blockers: pulmonary adenomas and carcinomas. Regul Toxicol Pharmacol 70: 555-563, 2014.
Received June 27, 2016

Revised July 20, 2016

Accepted July 21, 2016 